\title{
CORRECTION
}

\section{Correction to: Low-complexity disordered speech quality estimation}

\author{
Yousef S. Ettomi Ali ${ }^{1}$ (D) Vijay Parsa ${ }^{1,2} \cdot$ Philip Doyle $^{2} \cdot$ Soulaimane Berkane $^{3}$
}

Published online: 25 March 2020

(c) Springer Science+Business Media, LLC, part of Springer Nature 2020

\section{Correction to: International Journal of Speech Technology} https://doi.org/10.1007/s10772-020-09688-w

The original version of this article unfortunately contained a mistake in the PDF and HTML version. The spelling of the third author's name, Philip Doyle, has been corrected. Additionally, the affiliation for Vijay Parsa and
Philip Doyle is 'School of Communication Sciences and Disorders'.

Publisher's Note Springer Nature remains neutral with regard to jurisdictional claims in published maps and institutional affiliations.

The original article has been updated.

The original article can be found online at https://doi.org/10.1007/ s10772-020-09688-w.

Yousef S. Ettomi Ali

yali23@uwo.ca

Vijay Parsa

parsa@nca.uwo.ca

Philip Doyle

pdoyle@uwo.ca

Soulaimane Berkane

berkane@kth.se

1 Department of Electrical and Computer Engineering, University of Western Ontario, London, ON, Canada

2 School of Communication Sciences and Disorders, University of Western Ontario, London, ON, Canada

3 Department of Computer Sciences and Engineering, University of Quebec in Outaouais, Gatineau, QC, Canada 